\title{
Citation Guidelines
}

$$
\text { for Nuclear Data }
$$

Retrieved from Databases Resident at

$$
\text { the Nuclear Data Centers Network }
$$

written by

Victoria Mclane

on behalf of the

Nuclear Data Centers Network

July 1996

National Nuclear Data Center Brookhaven National Laboratory Upton, NY 11973-5000 



\section{Table of Contents}

Introduction $\ldots \ldots \ldots \ldots \ldots \ldots \ldots \ldots \ldots \ldots \ldots \ldots \ldots \ldots \ldots$

Data Source $\ldots \ldots \ldots \ldots \ldots \ldots \ldots \ldots \ldots \ldots \ldots \ldots \ldots \ldots \ldots$

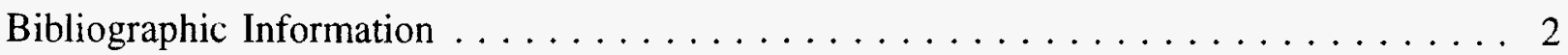

Nuclear Science References $(\mathrm{NSR}) \ldots \ldots \ldots \ldots \ldots \ldots \ldots \ldots \ldots$

Computerized Index to Neutron Data $($ CINDA $) \ldots \ldots \ldots \ldots \ldots$

Experimental Reaction Data $\ldots \ldots \ldots \ldots \ldots \ldots \ldots \ldots \ldots \ldots \ldots \ldots \ldots \ldots \ldots \ldots \ldots$

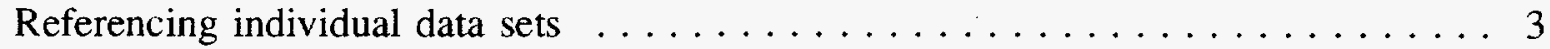

Referencing the EXFOR format $\ldots \ldots \ldots \ldots \ldots \ldots \ldots \ldots \ldots \ldots \ldots \ldots \ldots$

Referencing the CSISRS online database $\ldots \ldots \ldots \ldots \ldots \ldots \ldots$

Evaluated Data Libraries in the ENDF Format $\ldots \ldots \ldots \ldots \ldots \ldots$

Referencing individual evaluations $\ldots \ldots \ldots \ldots \ldots \ldots \ldots \ldots \ldots \ldots \ldots \ldots \ldots$

Referencing an evaluated library $\ldots \ldots \ldots \ldots \ldots \ldots \ldots \ldots \ldots \ldots \ldots \ldots \ldots \ldots \ldots \ldots$

Referencing the ENDF Format $\ldots \ldots \ldots \ldots \ldots \ldots \ldots \ldots \ldots \ldots \ldots \ldots \ldots \ldots \ldots \ldots$

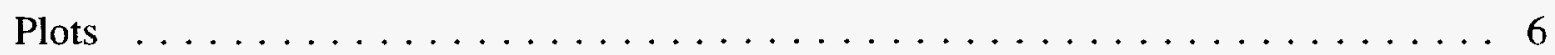

Multigroup Libraries $\ldots \ldots \ldots \ldots \ldots \ldots \ldots \ldots \ldots \ldots \ldots \ldots \ldots \ldots \ldots \ldots \ldots \ldots$

Evaluated Nuclear Structure Data

Evaluated Nuclear Structure Data File $($ ENSDF) $\ldots \ldots \ldots \ldots \ldots \ldots \ldots$

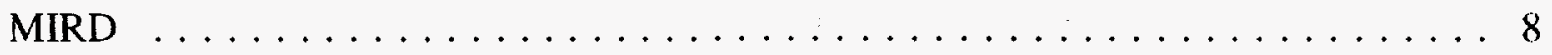

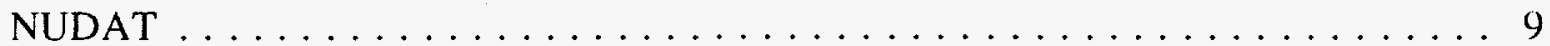

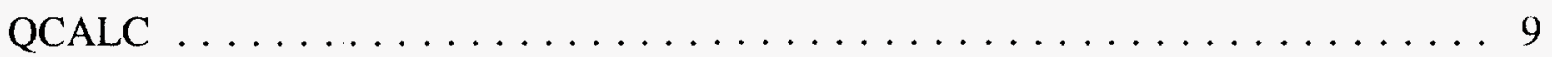

Photo Atomic Interaction Data $\ldots \ldots \ldots \ldots \ldots \ldots \ldots \ldots \ldots \ldots$

Attenuation Coefficients $\ldots \ldots \ldots \ldots \ldots \ldots \ldots \ldots \ldots \ldots \ldots$

Polarized Scattering $\ldots \ldots \ldots \ldots \ldots \ldots \ldots \ldots \ldots \ldots \ldots \ldots$

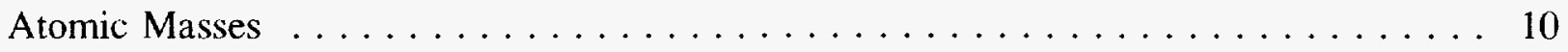

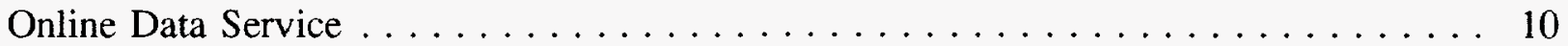

Appendix A: Nuclear Data Centers Network

Appendix B: International Nuclear Structure and Decay Data Network 


\section{Acknowledgements}

This work was performed under the auspices of the U. S. Department of Energy, Division of Nuclear Physics, Office of Energy Research.

The author would like to thank H. D. Lemmel of the IAEA Nuclear Data Section and T. W. Burrows of the NNDC for their significant contributions. The author would also like to thank the other members of the NNDC who contributed, especially J. K. Tuli and C. L. Dunford. 


\section{Introduction}

This documents outlines the proper method of citing data obtained from each of the Nuclear Data Centers Network databases.

The Nuclear Data Centers Network ${ }^{1}$ is a world-wide cooperation of nuclear data centers under the auspices of the International Atomic Energy Agency. The Network organizes the task of collecting, compiling, standardizing, storing, assessing, and distributing the nuclear data on an international scale. Information available at the Centers includes bibliographic, experimental, and evaluated databases for nuclear reaction data and for nuclear structure and radioactive decay data. The objective of the Network is to provide the information to users in a convenient, readilyavailable form. To this end, online data services have been established at three of the centers: the National Nuclear Data Center (NNDC), the Nuclear Data Section of the International Atomic Energy Agency (NDS), and the OECD Nuclear Energy Agency Data Bank (NEADB). Some information is also available at the NNDC and NEADB WorldWideWeb sites.

\section{Data source}

Data obtained from the databases residing at the member organizations of the Nuclear Data Centers Network should be properly cited. In general, there should be a citation of the original source of the information used, as well as of the database from which the data were extracted. The source of the information should be cited as:

- Data retrieved (or extracted) from the (center name) Online Data Service,

- Data retrieved (or extracted) from the (center name) WorldWideWeb site,

- Data received by electronic file transfer from (center name),

- Data received from (center name) $)^{2}$.

These data bases may contain essential information which does not exist in a published article. Since the databases are periodically updated, it is important to include the date and/or revision number of the version of the database used.

1 The Nuclear Data Center Network and the participating centers are described in report INDC(NDS)-324 (1195).

2 For information received by mail or electronic mail. 


\section{Bibliographic Information}

When information retrieved from one of the Centers' bibliographic databases is used in a review article or other survey of available information, the database used should be cited; the citation should include the version (date) of the database used.

\section{Nuclear Science References (NSR)}

Data included in Nuclear Science References are compiled, checked, organized, and distributed by the National Nuclear Data Center. ${ }^{3}$ The database should be cited as follows.

National Nuclear Data Center, Nuclear Science References, version of (date). Information extracted from the NSR database /Source].

The citation to be used when citing the NSR formats is:

S. Ramavataram and C.L. Dunford, Nuclear Science References Coding Manual, Report BNL-NCS-51800, Rev. 08/96 (1996) Brookhaven National Laboratory, U.S.A.

\section{Computerized Index to Neutron Data (CINDA)}

Data included in CINDA are compiled by the Neutron Data Centers (i.e., NNDC, NEADB, NDS, and the Russian Nuclear Data Center (CJD)). The database should be cited as follows.

Nuclear Data Centers Network, CINDA95, Index to the Literature and Computer Files on Microscopic Neutron Data, ${ }^{4}$ (International Atomic Energy Agency, Vienna, Austria, 1995). Information extracted from the CINDA database, version (date), [Source].

The CINDA format should be cited as follows:

NEA Data Bank, CINDA Coding Manual, unpublished, February 1990.

${ }^{3}$ Contributions to the compilation of Japanese references are made by the Institute of Physical and Chemical Research (RIKEN), Japan, and of Russian references by at the St. Petersburg Nuclear Physics Institute, Gatchina.

${ }_{4}$ The CINDA publication is issued every year. Please refer to the latest issue. 


\section{Experimental Reaction Data}

The data in the Experimental Nuclear Reaction Database are compiled in the EXFOR format and exchanged among the members of the Nuclear Data Centers Network (see Appendix A). ${ }^{5}$

\section{Referencing individual data sets}

When citing data extracted from this database, always cite the individual references. However, the data entries are often more up-to-date than the original reference; the entries may be updated, sometimes repeatedly, either when the author revises the data, or when the EXFOR compiler receives additional information about the data. Therefore, for unique identification of the data used, the EXFOR data set should also be referenced, and the date of the last revision should be given. ${ }^{6}$ (Note that the authors receive proof copies of the data before it is entered into the database and in the case of any major revision to the data set).

\section{Example:}

A.B. Author, et al., J. Nucl. Phys. 12, 345 (1979). Data retrieved from the CSISRS database, file EXFOR 12345.002 dated April 5, 1980 [Sour ce] .

Notes on finding the information needed to reference a data set:

1. The authors of an EXFOR/CSISRS data set may be found under the keyword 'AUTHOR' in the BIB section.

2. References for the data given in an EXFOR entry may be found under the keyword 'REFERENCE' in the BIB section. If more than one reference is given, the first is the primary reference.

3. The subentry number of the data set (e.g., 12345. or 12345.002) will be given at the beginning of each data set displayed in an online retrieval, or, for a file in the EXFOR format, may be found on the SUBENT record of the data set, immediately following the SUBENT keyword.

4. The revision date will be given at the beginning of each data set displayed in an online retrieval, or, for a file in the EXFOR format, is given on the SUBENT record of the data set, immediately following the data set number. The format of the date is yymmdd, where $y y$ is the last 2 digits of the year, $m m$ is the integer equivalent for the month, and $d d$ is the day of the month.

5 This data is available from the CSISRS database at NNDC and NDS, and from the EXFOR database at NEADB.

6 Do not use old EXFOR retrievals. In case of doubt, check with the Data Center responsible for the database from which you retrieved the data. 


\section{Referencing the EXFOR format}

To reference the EXFOR data in general, for example, when discussing the EXFOR format, the citation to be used is:

Nuclear Data Centers Network, EXFOR Systems Manual: Nuclear Reaction Data Exchange Format, Report BNL-NCS-63330 (1996), compiled and edited by V. McLane, National Nuclear Data Center, Brookhaven National Laboratory, U.S.A.

\section{Referencing the CSISRS database}

For the reference to be used when citing the CSISRS database, see Online Data Service, page 10.

When using plots produced from the CSISRS database, the citation should read:

Plots produced using the code BNL325, written by C.L. Dunford, National Nuclear Data Center, Brookhaven National Laboratory.

\section{Evaluated Data Libraries in the ENDF Format}

Five major evaluated nuclear data libraries are produced in the ENDF format and exchanged by the members of the Nuclear Data Centers Network: BROND, CENDL, ENDF/B, JEF, and JENDL. Each of these libraries is maintained by one of the member Centers.

\section{Referencing individual evaluations}

For individual evaluations, the reference should contain the author of the evaluation, along with a reference to the appropriate documentation. In addition, the library name, MAT number, the MOD or revision number, and the institution(s) which are responsible for the evaluation should be included. All these data are readily available in File 1, MT 451, of each evaluation. Where a published document prepared by the authors of the evaluation is available, this document should be cited directly. If such a document does not exist, the documents describing the contents of the library from which the data has been extracted should be used as a reference (see Referencing an Evaluated Library, following).

A.B. Name, Report ANL/NDM-129 (1994), Argonne National Laboratory, U.S.A., ENDF/B-VI evaluation, MAT \# 4831, Revision 1, July 1995; data retrieved from the ENDF database [Source] . 


\section{Referencing an evaluated library}

The following citations are proposed for referencing a specific evaluated data library in its entirety.

\section{$\underline{\text { BROND-2 }}$}

The Russian Library of Evaluated Neutron Reaction Data is produced and maintained by the Russian Nuclear Data Center (CJD). The most current version of this library is BROND-2; the citation should read:

A. I. Blokhin, et al., Current Status of Russian Nuclear Data Libraries, Nuclear Data For Science and Technology, Volume 2, p. 695, edited by J. K. Dickens (American Nuclear Society, LaGrange Park, IL, 1994).

\section{CENDL-2}

The Chinese Evaluated Nuclear Data Library is produced by the Chinese Nuclear Data Center and the Nuclear Data Committee of China, and is maintained by the Chinese Nuclear Data Center. The most current version of this library is CENDL-2; the citation should read:

Chinese Nuclear Data Center, CENDL-2, The Chinese Evaluated Nuclear Data Library for Neutron Reaction Data, Report IAEA-NDS-61, Rev. 3 (1996), International Atomic Energy Agency, Vienna, Austria.

\section{$\underline{\text { ENDF/B-VI }}$}

The Evaluated Nuclear Data File (ENDF/B) is produced by members of the Cross Section Evaluation Working Group, and is maintained by the National Nuclear Data Center. The current version of this library is ENDF/B-VI; the citation should read:

Cross Section Evaluation Working Group, ENDF/B-VI Summary Documentation, Report BNL-NCS-17541 (ENDF-201) (1991), edited by P.F. Rose, National Nuclear Data Center, Brookhaven National Laboratory, Upton, NY, USA.

\section{JEF-2}

The Joint Evaluated File (JEF) is produced by the NEA Joint Evaluation Project, and maintained by the NEA Data Bank. The current version of this library is JEF-2; the citation should read:

C. Nordborg, M. Salvatores, Status of the JEF Evaluated Data Library, Nuclear Data for Science and Technology, edited by J. K. Dickens (American Nuclear Society, LaGrange, IL, 1994).

\section{JENDL-3}

The Japanese Evaluated Nuclear Data Library is produced by the JAERI Nuclear Data Center and the Japanese Nuclear Data Committee, and is maintained by the JAERI Nuclear Data Center; the current version of the library is JENDL-3; the citation should read:

T. Nakagawa, et al., Japanese Evaluated Nuclear Data Library, Version 3, Revision 2, J. Nucl. Sci. Technol. 32, 1259 (1995). 


\section{Referencing the ENDF format}

The citation to be used when referencing the ENDF format is:

The Cross Section Evaluation Working Group, Data Formats and Procedures for the Evaluated Nuclear Data File ENDF-6, Report BNL-NCS-44945 (ENDF-102) (1995) edited by V.McLane, et al., National Nuclear Data Center, Brookhaven National Laboratory, U.S.A.

For the reference to be used when citing the ENDF database, see Online Data Service, page 10.

\section{Plots}

When using tables and drawings produced from the ENDF database through the Online Data Service at NNDC or NDS, the citation should read:

Plots produced using the Online Service retrieval code package written by C. L. Dunford, National Nuclear Data Center, Brookhaven National Laboratory.

\section{Multigroup Libraries}

If the evaluated data are used to generate a multigroup library, the report describing the multigroup library should contain a table referencing the evaluations used. The table should include the library name and version, material, material number (MAT), modification number (MOD) or revision number, authors, and institution for each evaluation.

\section{Example:}

$\begin{array}{lcccll}\text { Library } & \text { Material } & \text { MAT \# } & \text { MOD } & \text { Author } & \text { Institute } \\ \text { ENDF/B-VI } & { }^{58} \mathrm{Ni} & 2825 & 2 & \text { D. Larson, et al. } & \text { ORNL } \\ \text { JENDL-3 } & { }^{62} \mathrm{Ni} & 2837 & 3 & \text { S. lijima } & \text { NAIG }\end{array}$




\title{
Evaluated Nuclear Structure Data
}

\author{
Evaluated Nuclear Structure Data File (ENSDF) \\ ENSDF is produced by the International Nuclear Structure and Decay Data Network (see \\ Appendix B), and is maintained by the National Nuclear Data Center. ${ }^{7}$ The data are available \\ at the National Nuclear Data Center, the NEA Data Bank, IAEA Nuclear Data Section, the \\ Russian Nuclear Data Center (CJD), and the Russian Nuclear Structure and Reaction Data Center \\ (CaJaD) (see Appendix A).
}

\section{$\underline{\text { Referencing individual evaluations }}$}

To reference individual mass chains or parts of mass chains, cite the author and the published version of the evaluation. This will be found under MASS_STATUS when accessing the ENSDF database through the Online Data Service, or toward the end of the COMMENTS data set of the mass chain. The citation will automatically be generated if the data are displayed using the code ENSDAT.

\section{Example:}

COMMENT section records:

56 C AUTH HUO JUNDE

56 C CIT\$NDS 67, 523 (1992)

Citation:

Huo Junde, Nucl. Data Sheets 67, 523 (1992). Data extracted from the ENSDF database, version (date), /Sourcel.

Many mass chains are periodically updated between published evaluations. In this case, a reference to the database version should be included in the citation. For example, an evaluation published in the Nuclear Data Sheets in 1990 will have 90NDS on the first record of the ENDFformatted data set; if the data set was revised in 1993 based on new data, 90NDS+93 will appear at the right on this record, followed by the date of entry into the database. The COMMENTS data set will contain information on the revision, and there should also be documentation in the data set.

\section{Example:}

1st record of COMMENT section:

\section{COMMENTS}

90NDS+93 931112

Citation:

T.W. Burrows, Nucl. Data Sheets 61, 1 (1990), and interim evaluation, T.W. Burrows

(1993). Data extracted from the ENSDF database, revision of Nov. 11, 1993, [Source].

7 The Network is described in the IAEA Nuclear Data Newsletter, issue 20 (1994).

8 For data processed through the Online Service at NNDC or NDS, the plots are generated using the code ENSDAT. 


\section{Referencing ENSDF}

When referencing the Evaluated Nuclear Structure Data File (ENSDF) as a whole, for example, if the data used span many mass chains as in a study of systematics, the citation should include the revision date of the database. The citation should read, for example:

Data extracted using the NNDC On-Line Data Service from the ENSDF database, file revised as of (date). M. R. Bhat, Evaluated Nuclear Structure Data File (ENSDF), Nuclear Data for Science and Technology, page 817, edited by S. M. Qaim (SpringerVerlag, Berlin, Germany, 1992).

\section{Referencing the ENSDF format}

The reference to be used when citing the ENSDF format is:

J.K. Tuli, Evaluated nuclear structure data file, Nucl. Instr. Meth. A 369, 506 (1996).

For the reference to be used when citing the ENSDF database, see Online Data Service, page 10.

\section{Prepublication Data}

Data obtained from the prepublication data base should be treated as a preprint. It should not be cited without express permission of the authors.

\section{$\underline{\text { Tables and Figures }}$}

When using tables and figures produced by the NNDC or NDS Online Service, the citation should read:

Plots produced using the code ENSDAT, written by R.R. Kinsey, National Nuclear Data Center, Brookhaven National Laboratory, Upton, NY, U.S.A.

\section{MIRD}

When using data extracted from the MIRD database, the citation should read, for example:

Data produced using the MIRD Program, and extracted from the Evaluated Nuclear Structure Data File (ENSDF), date, [Source] . Additional calculations performed by the program RADLST, T.W. Burrows, The Program RADLST, Report BNL-NCS-52142 (1988), National Nuclear Data Center, Brookhaven National Laboratory, U.S.A. 


\section{NUDAT}

Data retrieved from the NUDAT database should have the following citation with reference to the Online Data Service used and the version date of the file.

R. R. Kinsey, et al., The NUDAT/PCNUDAT Program for Nuclear Data, paper submitted to the 9th International Symposium of Capture-Gamma-Ray Spectroscopy and Related Topics, Budapest, Hungary, October 1996. Data extracted from the NUDAT database, version (date), [Source] ...

\section{QCALC}

To reference calculations performed by the program QCALC:

Data produced by the code QCALC, written by T.W. Burrows, National Nuclear Data Center, Brookhaven National Laboratory, and based on the Audi-Wapstra Atomic Mass Tables, G. Audi and A.H. Wapstra, The 1995 Update to the Atomic Mass Evaluation., Nucl. Phys. A595, 409 (1995).

\section{Photo-Atomic Interaction Data}

When referencing calculations from the XRAY program, the Online Data Service from which the data were extracted should be referenced. The following specific citations should be made depending on the calculations performed.

Data extracted from the XRAY database, version (date), [Sour ce] ...

The following citations should be appended depending on the type of data used.

\section{Attenuation Coefficients}

...using a modification of the program XCOM, M.J. Berger and J.H. Hubbell, XCOM: Photon Cross Sections on a Personal Computer, Report NBSIR 87-3597 (1987), National Institute for Standards and Technology, U.S.A.

\section{Polarized Scattering}

\section{Photon-interaction Data}

...using photon-interaction data are taken from the ENDF/B-VI library, D.E. Cullen, et al., Tables and Graphs of Photon-Interaction Cross Sections from $10 \mathrm{eV}$ to $100 \mathrm{GeV}$ Derived from the LLNL Evaluated Photon Data Library (EPDL), Report UCRL-50400, Vol. 6, Parts A+B (1989), Lawrence Livermore National Laboratory, U.S.A.

\section{Polarized scattering calculations}

... and based on work by A.L. Hanson, Nucl. Instr. Meth. A 290, 167-171 (1990), Nucl.

Instr. Meth. A 264, 471-483 (1988), and Nucl. Instr. Meth. A 264, 484-487 (1988). 


\section{Atomic Masses}

Data taken from the MASSES library, should be referenced as follows.

G. Audi and A.H. Wapstra, The 1995 Update to the Atomic Mass Evaluation., Nucl. Phys. A595, 409 (1995). Data extracted from the MASSES library [Sour ce].

\section{Online Data Service}

The reference to be used in citing the Online Data Service systems are:

At NNDC and NDS:

C.L. Dunford and T.W. Burrows, Online Nuclear Data Service, Report IAEA-NDS-150 (NNDC Informal Report NNDC/ONL-95/10), Rev. 95/10 (1995) ${ }^{9}$, International Atomic Energy Agency, Vienna, Austria.

At NEADB:

General User's Guide to the NEA Online Services, Report DBG-030.11 (1993), NEA Data Bank, Paris, France.

9 Periodically updated. 
Appendix A

Nuclear Data Centers Network 
National Nuclear Data Center

Bldg. 197D

Brookhaven National Laboratory

P. O. Box 5000

Upton, NY 11973-5000

U.S.A.
Contact: Dr. Charles L. Dunford

Phone: +1 516-344-2902

Fax: +1 516-344-2806

Internet: nndc@bnl.gov

WorldWideWeb: http://www.nndc.bnl.gov

Telnet (online): bnlnd2.dne.bnl.gov username: NNDC; code: GUEST

FTP: bnlnd2.dne.bnl.gov username: ANONYMOUS

OECD Nuclear Energy Agency Data Bank Le Seine Saint-Germain

12, Boulevard des Iles

92130 Issy-les-Moulineaux

FRANCE

\author{
I.A.E.A. Nuclear Data Section \\ Wagramerstr. 5, P. O. Box 100 \\ A-1400 Wien \\ AUSTRIA
}

Federal Research Center IPPE

Centr Yadernykh Dannykh

Ploschad Bondarenko

249020 Obninsk, Kaluga Region

RUSSIA

Russian Nuclear Data Center

Kurchatova Institute of Atomic Energy

46 Ulitsa Kurchatov

123182 Moscow

RUSSIA

Institute of Nuclear Physics

Moscow State University

Vorob'evy Gory

119899 Moscow

RUSSIA
Phone: +33145241071

Fax: +33145241110

Internet: nea@nea.fr

WorldWideWeb:

http://www.nea.fr/html/dbdata/dbdata.html

Telnet (online): db.nea.fr

username: NEADB; code: GUEST

FTP: ftp.nea.fr; username: ANONYMOUS

Contact: Dr. Douglas Muir

Phone: +431206021709

Fax: +43120607

Internet: muir@iaeand.iaea.or.at

Telnet (online): iaeand.iaea.or.at username: IAEANDS; code: GUEST

FTP: iaeand.or.at; unername: ANONYMOUS

Contact: Dr. Vasili N. Manokhin

Phone: +7 0843998982

Fax: +70958833112

Internet: manokhin@cjd.obninsk.su

Contact: Dr. Felix E. Chukreev

Phone: +7 0951961612

Fax: +70959430073

Internet: chukreev@cajad.kiae.su

Dr. Vladimir V. Varlamov

Phone: +7 0959393483

Fax: +70959390896

Internet: varlamov@cdfe.npi.msu.su
Contact: Dr. Nigel Tubbs 
China Nuclear Data Center

China Institute of Atomic Energy

P.O. Box 275 (41), Beijing

PEOPLE'S REPUBLIC OF CHINA

Institute of Nuclear Research

Hungarian Academy of Sciences

P.O. Box 51

H-4001 Debrecen

HUNGARY

Nuclear Data Center

Japan Atomic Energy Research Institute

Tokai-Mura, Naka-Gun

Ibaraki-Ken 319-11

JAPAN

Institute of Physical \& Chemical Research (RIKEN)

2-1 Hirosawa, Wako-shi

Saitama-Ken 351-01

JAPAN

Department of Physics

Hokkaido University

Kita-10 Nishi-8, Kita-ku

Sapporo 060

JAPAN
Contact: Dr. Zhang Zingshang

Phone: +8619357005

Fax: +8619357008

Internet: ciaednp@bepc2.ihep.ac.cn

Contact: Dr. F. T. Tárkányi

Phone: 361 52-417-266

Fax: 361 52-416-181

Internet: "h3817tar@ella.hu"

Contact: Dr. Yasuyuki Kikuchi

Phone: +81292825480

Fax: +81292826122

Internet: kikuchi@cracker.tokai.jaeri.go.jp

Contact: Dr. Yoshihiko Tendow

Phone: +81 484621111 Ext: 3272

Fax: +81484624641

Internet: tendow@postman.riken.go.jp

Contact: Dr. Kiyoshi Kato

Phone: 81 11-386-8111

Fax: 81 11-386-8113

Internet: kato@nucl.phys.hokudai.ac.jp 
Appendix B

International Nuclear Structure and Decay Data Network 
I.A.E.A. Nuclear Data Section

Wagramerstr. 5, P. O. Box 100

A-1400 Wien

AUSTRIA

Laboratorium voor Kernfysica

Proeftuinstraat 86

B-9000 Gent

BELGIUM

Dept. of Physics and Astronomy

McMaster University

Hamilton, ONL8S 4M1

CANADA

Chinese Nuclear Data Center

Institute of Atomic Energy

P.O. Box 275 (41), Beijing

People's Republic of CHINA

Atomic Mass Data Center

Batiment 108

Centre de Spectrometrie Nucleaire et de

Spectrometrie de Masse

F-91405 Campus Orsay

FRANCE

Centre d'Etudes Nucleaires

DRF-SPH, Cedex No. 85

F-38041 Grenoble Cedex

FRANCE

OECD Nuclear Energy Agency Data Bank

Le Seine Saint-Germain

12, Boulevard des lles

92130 Issy-les-Moulineaux

FRANCE

Nuclear Data Center

Tokai Research Establishment

Japan Institute of Atomic Energy

Tokai-Mura, Naka-Gun

Ibaraki-Ken 319-11

JAPAN
Contact: Dr. Pavel Oblozinsky

Phone: +431206021712

Fax: +43120607

Internet: oblozinsky@iaeand.iaea.or.at

Contact: Dr. D. De Frenne

Phone: +3292646532

Fax: +32 92646699

Internet: inwff@inwnrf.rug.ac.be

Contact: Dr. Balraj Singh

Phone: 1 905-525-9140 EXT: 23631

Fax: 1 905-335-8540

Internet: balraj@mcmaster.ca

Contact: Zhang Zingshang

Phone: +8919357005

Internet: ciaednp@bepc2.ihep.ac.cn

Contact: Dr. Georges Audi

Phone: +33169415223

Fax: +33169415268

Internet: audi@frcpn11.in2p3.fr

Contact: Dr. Jean Blachot

Phone: +3376883926

Fax: +3376885153

Internet: jblacho@drfmc.ceng.cea.fr

Contact: Dr. Nigel Tubbs

Phone: +331 45241071

Fax: +33145241110

Internet: tubbs@nea.fr

Contact: Dr. Y. Kikuchi

Phone: +81292825480

Fax: +81292826122

Internet: kikuchi@cracker.tokai.jaeri.go.jp 
Nuclear Data Project

Kuwait Institute for Scientific Research

P.O. Box 24885

Kuwait

KUWAIT

Fysisch Laboratorium

Princetonplein 5, Postbus 80.000

3508 TA Utrecht

The NETHERLANDS

NIKHEF-K

P.O. Box 4395

NL-1009 AL Amsterdam

The NETHERLANDS

Center for Nuclear Structure and Reaction Data

I.V. Kurchatova Institute of Atomic Energy

46 Ulitsa Kurchatov 123182

Moscow

RUSSIA

Nuclear Data Centre

St Petersburg Nuclear Physics Institute

Gatchina, Leningrad Region 188350

RUSSIA

Department of Physics

University of Lund

Sölvegatan 14

S-223 62 Lund

SWEDEN

Center for Nuclear Information Technology

Dept. of Chemistry

San Jose State University

San Jose, CA 95192-0101

U.S.A.

Idaho National Engineering Laboratory

Lockheed Idaho Technologies Co.

Idaho Falls, ID 83415-2211

U.S.A.

Nuclear Science Division
Contact: Dr. A. R. Farhan

Phone: +9654849558

Fax: +965 4819374

Internet: ameenah@kuc01.kuniv.edu.kw

Contact: Dr. C. van der Leun

Phone: +31 30532513

Fax: +3130518689

Contact: Dr. A.H. Wapstra

Phone +31 205922163

Fax: +31 205922195

Internet: wapstra@nikhefk.nikhef.nl

Contact: Dr. F. E. Chukreev

Phone: +7 0951961612

Fax: +70959430073

Internet: chukreev@cajad.kiae.su

Contact: Dr. I. Kondurov

Phone: +7 8127130569

Fax: +78127136051

Internet: igork@hep486.pnpi.spb.ru

Contact: Dr. Peter Ekström

Phone: +46 46107647

Fax: +46 46104709

Internet: peter.ekstrom@nuclear.lu.se

Contact: Dr. Craig A. Stone

PHONE: +1 408-924-4940 or

FAX: +1 408-924-4945

Internet: stone.c@applelink.apple.com

Contact: Dr. Richard G. Helmer

Phone: +1 208-526-4157

Fax: +1 208-526-9267

Internet: rhz@inel.gov

Contact: Dr. Janis M. Dairiki 
MS 70A-3307

Lawrence Berkeley National Laboratory

University of California

Berkeley, CA 94720

U.S.A.

- National Nuclear Data Center

Bldg. 197D

Brookhaven National Laboratory

Upton, NY 11973-5000

U.S.A.

Triangle Universities Nuclear Laboratory

P.O. Box 90308

Durham, NC 27708-0308

U.S.A.

Nuclear Data Project

Physics Division, Bldg. 6000, MS 6371

Oak Ridge National Laboratory

P.O. Box 2008

Oak Ridge, TN 37831-6371

U.S.A.
Phone: +1 510-486-5673

Fax: +1 510-486-4808

Internet: dairiki@lbl.gov

Contact: Dr. Charles L. Dunford

Phone: +1 516-282-2804

Fax: +1 516-282-2806

Internet: dunford@bnlnd2.dne.bnl.gov

Contact: Prof. D. R. Tilley

Phone: +1 919-660-2625

Fax: +1 919-660-2634

Internet: tilley@tunl.duke.edu

Contact: Dr. Murray J. Martin

Phone: +1 615-574-4691

Fax: +1 615-574-1268

Internet: martinm@orph01.phy.ornl.gov 


\section{DISCLAIMER}

This report was prepared as an account of work sponsored by an agency of the United States Government. Neither the United States Government nor any agency thereof, nor any of their employees, makes any warranty, express or implied, or assumes any legal liability or responsibility for the accuracy, completeness, or usefulness of any information, apparatus, product, or process disclosed, or represents that its use would not infringe privately owned rights. Reference herein to any specific commercial product, process, or service by trade name, trademark, manufacturer, or otherwise does not necessarily constitute or imply its endorsement, recommendation, or favoring by the United States Government or any agency thereof. The views and opinions of authors expressed herein do not necessarily state or reflect those of the United States Government or any agency thereof. 